\title{
Produção de sabão derivado do óleo vegetal: o caso da UEPA Marabá, Pará
}

O descarte inadequado do óleo de cozinha residual utilizado em residências e ainda em estabelecimentos comerciais como restaurantes e lanchonetes tornou se um agravante da poluição devido a sua 'invalidez' pós uso. No Brasil, de acordo com a Associação Brasileira das Indústrias de Óleos Vegetais - ABIOVE, a produção de óleo de cozinha em 2016 foi de 7.885 mil toneladas; a projeção segundo a mesma, para o ano de 2017 é de 8.200 mil toneladas de óleo de soja. Este trabalho sugere a alternativa da produção e análise laboratorial do sabão ecológico como uma forma de reciclagem do óleo de cozinha residual coletado na lanchonete da Universidade do Estado Pará, no campus VIII (Marabá), bem como, a divulgação do trabalho à comunidade por meio de oficinas como uma forma de sustentabilidade e educação ambiental. Para o desenvolvimento do trabalho, coletou se 10 litros do material proveniente da fritura durante um período de 20 dias, que serviram de base para se obter uma média diária do óleo de cozinha residual gerado. Houve a produção para fins de análises e após a interpretação dos resultados período de 20 dias, que serviram de base para se obter uma média diária do óleo de cozinha residual gerado. Houve a produção para fins de análises e após a interpretação dos resultados oficinas de produção de sabão: a primeira, realizada em junho com estudantes do próprio campus; e a segunda, realizada em outubro, com a participação de funcionárias do setor de serviço gerais do próprio campus e da SEAGRI - Secretaria Municipal de Agricultura de Marabá- PA. Mais que a preservação do meio ambiente e os seus recursos naturais, a reciclagem do óleo para produção de sabão em barra ou líquido gera ganhos econômicos, por ser obtido a um custo inferior que aquele para obter o produto comercial. Constatou-se, com realização das oficinas, que os participantes estão se preocupando mais com a preservação do meio ambiente e requisitando mais ações que visam melhorar a qualidade de vida sem prejudicar o meio em que vivem.

Palavras-chave: Descarte inadequado; Reciclagem; Educação ambiental.

\section{Production of soap derived from vegetable oil: the case of UEPA Marabá, Pará}

The inadequate disposal of residual cooking oil used in homes, as well as in commercial establishments such as restaurants and snack bars; has become an aggravating environmental pollution al through as a form of sustainability and environmental education. For the development of the work, we collected 10 liters of the material from the frying during a period of 20 days, which served as the basis for obtaining a daily average of cooking oil generated residual. There was production for analysis purposes and after interpretation of the results in an experimental manner according to the appropriate specifications of the chemical characteristics of the soap and based on the opinion of those involved with the application of the questionnaire, two soap production workshops were held: the first, held in June with students from the campus itself; and the second, held in October, with the participation of employees from the general services sector of the campus itself and SEAGRI - Municipal Secretary of Agriculture of Marabá-PA. More than the preservation of the environment and its natural resources, the recycling of the oil for the production of bar soap or liquid generates economic gains, being obtained at a lower cost than the one to obtain the commercial product. It was found, with the realization of the workshops, that the 3 participants are more concerned with preserving the environment and requesting more actions that aim to improve the quality of life without harming the environment in which they live.

Keywords: Inadequate disposal; Recycling; Environmental education.

Topic: Desenvolvimento, Sustentabilidade e Meio Ambiente

Reviewed anonymously in the process of blind peer.
Received: 11/03/2020

Approved: 11/04/2020
Stephanie Jael Negrão de Freitas Universidade Federal do Pará, Brasil http://lattes.cnpq.br/1432769722634758 http://orcid.org/0000-0001-9917-5342 negro.stephanie@gmail.com

\section{Renan Alves Brito (ID)}

Universidade do Estado do Pará, Brasil http://lattes.cnpq.br/8892818284490658 http://orcid.org/0000-0001-6668-8088 renanalves 1@hotmail.com

Railson Miranda Barroso (iD

Universidade do Estado do Pará, Brasil http://lattes.cnpq.br/2539138246673380 http://orcid.org/0000-0003-1627-5941 railsonbarroso@hotmail.com
José Antônio de Castro e Silva (D) Universidade Federal do Pará, Brasil http://lattes.cnpq.br/7672943937723348 http://orcid.org/0000-0003-4569-3923 antoniocastrosilva@hotmail.com

Islia Lima de Sousa Amorim (iD Universidade do Estado do Pará, Brasil http://lattes.cnpq.br/2161191307542899 http://orcid.org/0000-0001-6629-5794 islia.amorimeng@gmail.com

Ana Carla Leite Carvalho Cabra Universidade da Amazônia, Brasil (it) http://lattes.cnpq.br/6538382004505294 http://orcid.org/0000-0002-1735-1320 calincarvalho@gmail.com
Amanda Lorenna Feio Gandra Instituto Tecnológico Vale, Brasil http://lattes.cnpq.br/7379950905410 http://orcid.org/0000-0002-7134-9651 amandagandra.337@gmail.com
Referencing this:

FREITAS, S. J. N.; BRITO, R. A.; BARROSO, R. M.; SILVA, J. A. C. AMORIM, I. L. S.; CABRAL, A. C. L. C.; GANDRA, A. L. F.. Produção de sabão derivado do óleo vegetal: o caso da UEPA Marabá, Pará. Nature and Conservation, v.13, n.2, p.47-57, 2020. DOI:

http://doi.org/10.6008/CBPC2318-2881.2020.002.0005 


\section{INTRODUÇÃO}

O descarte inadequado do óleo de cozinha residual utilizado em residências e ainda em estabelecimentos comerciais, tornou-se um agravante da poluição ambiental devido sua invalidez pós uso. Os efeitos negativos são inúmeros, onde conforme Belo (2014) provoca entupimento nas tubulações, refluxo e mau cheiro.

Quando o óleo alcança os corpos hídricos, de acordo com Macedo et al. (2016) pelo fato de o mesmo ter uma densidade menor que a água, ele se acumula na superfície dela impedindo a passagem de luz, quando em um ambiente de vida aquática, acarreta na morte de fitoplânctons (algas microscópicas que produzem oxigênio) que estão na base da cadeia alimentar dos seres aquáticos. Para se ter uma ideia, 1 litro de óleo despejado no esgoto doméstico tem capacidade para poluir mais de 25000 litros de água (SABESP, 2010).

Outra ação do óleo está em relação ao seu despejo irregular no solo, causando contaminação, que segundo Oliveira (2013) "ao atingir o solo, o óleo pode causar a impermeabilização, influenciando nas enchentes e no desenvolvimento de organismos". No Brasil, de acordo com a ABIOVE (2017) a produção de óleo de cozinha em 2016 foi de aproximadamente 7.885 mil toneladas; A projeção segundo a mesma, para o ano de 2017 é de 8.200 mil toneladas de óleo de soja. Em contrapartida, segundo Santos (2009), no Brasil são descartados 9,0 bilhões de litros/ano desse tipo de resíduo (óleo pós fritura), onde apenas 2,5\% é reciclado. $O$ restante é descartado inadequadamente junto ao meio ambiente, o que demonstra ser um dado preocupante.

Nezi et al. (2011) afirmam que a destinação final deste resíduo geralmente ocorre de quatro maneiras: esgotos, solo, corpos hídricos e aterros sanitários. Ressalta-se que dentre estes, até a forma menos agressiva ao meio ambiente, que é o aterro sanitário, são impróprios em graus e fatores diferentes, trazendo prejuízos para a sociedade civil, as formas de governo que os gerem e o meio ambiente que os mantém.

Ideias e propostas que visam o gerenciamento e beneficiamento do óleo de cozinha residual estão cada vez mais vorazes, de modo que Weyer et al. (2016) inferem que ele serve como material na produção de diferentes produtos, tais como: tintas, óleos para engrenagens, biodiesel, sabão, detergentes, glicerina, etc.. Sendo assim, o ciclo reverso do produto pode trazer benefícios competitivos e impedir a deterioração ambiental.

O processo de reciclagem do óleo de cozinha residual, além de benefícios socioambientais, influencia em crescimento econômico e financeiro, o que poderá ser comprovado em um estudo mais aprofundado sobre o assunto, mas que desde já aparentam significativa positividade sobre os resultados (NASCIMENTO et al., 2011).

A logística reversa do óleo de cozinha residual no ciclo produtivo, ao contrário de ser despejado no meio ambiente prejudicando-o, não é apenas uma ação ecologicamente correta e lucrativa, mas o procedimento beneficia até a qualidade de vida do cidadão brasileiro, uma vez que esse tipo de tratamento se torna oneroso devido à presença deste material na água, contaminando-a, o que é repassado em forma 
de impostos que são pagos pela própria população (SANTOS, 2009).

O presente artigo mostra de forma objetiva, didática e consciente a realização de um projeto que fora desenvolvido na Universidade do Estado do Pará, no campus VIII, em Marabá, onde produziu- se sabão líquido e sólido, através do óleo de cozinha residual, bem como a realização de testes de análises laboratoriais que comprovem a eficácia e eficiência do produto no processo de limpeza.

Este estudo sugere a produção e análise laboratorial do sabão ecológico como uma forma de reciclagem do óleo de cozinha residual coletado; bem como a divulgação do trabalho à comunidade por meio de oficinas, promovendo educação ambiental e ainda a relação custo benefício que o mesmo traz para a comunidade, sendo que o sabão ecológico apresenta viabilidade para o uso diário.

\section{MATERIAIS E MÉTODOS}

\section{Área de Estudo}

O estudo concentra-se na Universidade do Estado do Pará-UEPA (figura 1), localizada na cidade de Marabá, a qual pertence à mesorregião Sudeste Paraense. A sede municipal apresenta as seguintes coordenadas geográficas: 05 21' 54" Latitude Sul e 04우 07' 24" Longitude WGr. Com população estimada em 275.083 habitantes. No campus há por volta de setecentos e oitenta e três alunos matriculados entre dez cursos de graduação sob sistema regular e intervalar. O fluxo diário no mesmo é de aproximadamente seiscentas pessoas por dia, visto que a lanchonete da universidade oferece refeições matinais e noturnas de segunda à sábado.

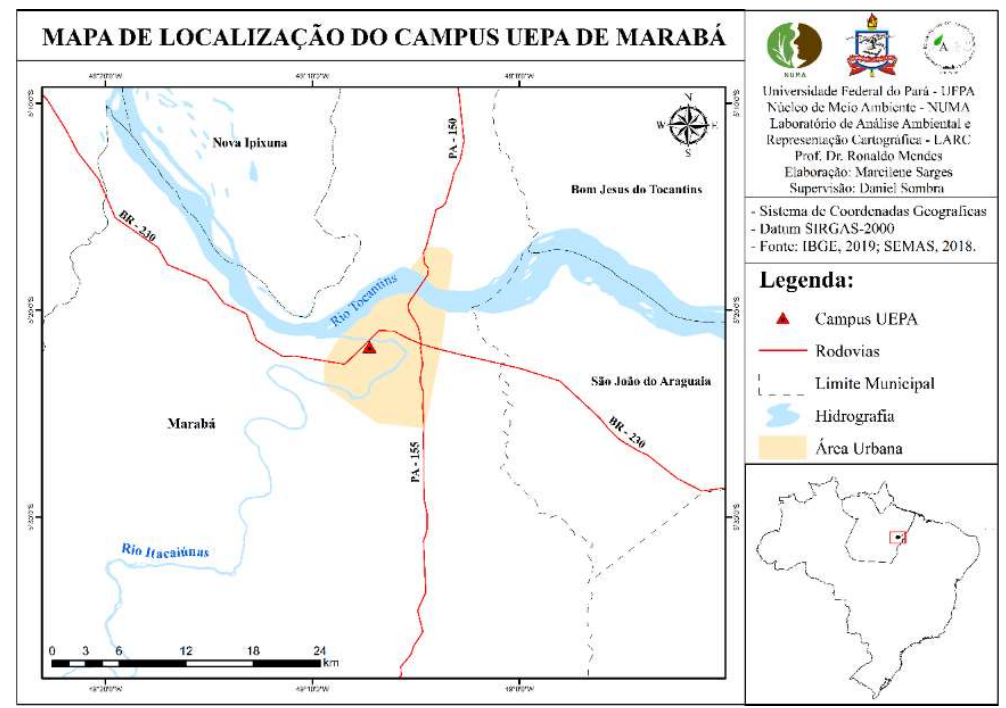

Figura 1: Campus da Universidade do Estado do Pará.

\section{Tipo de Pesquisa}

Este estudo se caracteriza como experimental, por conter processo laboratorial e também qualiquantitativo por haver entrevistas com parte da sociedade envolvida e quantificação dos resultados da produção de sabão ecológico. 


\section{Coleta de Dados}

Tendo como cenário de pesquisa a lanchonete do campus, primeiramente fora realizado um levantamento do percentual de óleo utilizado para o preparo dos alimentos. Os dados coletados dentro de um período de vinte dias foram o suporte para obter a média diária do óleo residual, sendo aproximadamente 1,5 L ao dia. Sendo que o proprietário do estabelecimento se disponibilizou a colaborar com a pesquisa oferecendo as informações necessárias.

\section{Analise de dados}

Para a produção artesanal do sabão de consistências sólida e líquida testaram-se oito metodologias diferentes na produção, chegando ao consenso que os melhores resultados a partir das análises, foram os métodos para o sabão sólido, para o sabão líquido, utilizadas de modo proporcional. Para os procedimentos de produção de sabão e análise laboratorial, foram utilizados os instrumentos e equipamentos, conforme descrito na tabela 1.

Tabela 1: Instrumentos e Equipamentos e suas respectivas utilidades para a produção de sabão ecológico

\begin{tabular}{|l|l|}
\hline INSTRUMENTO/EQUIPAMENTO & FUNÇÃO \\
\hline Béquer & Fazer reações entre soluções, dissolver substâncias sólidas. \\
\hline Proveta & Medição de líquidos \\
\hline Bastões de vidro & Utilizado em transportes de líquidos e agitação de soluções \\
\hline Espátula & Utilizado para mexer e misturar substâncias \\
\hline Erlenmeyer & Utilizado no processo de Titulação \\
\hline Balão de fundo redondo & utilizado nas destilações químicas \\
\hline Balão Volumétrico & Utilizado para preparação e diluição de soluções com volumes precisos e pré-fixados \\
\hline Recipiente de plástico (capacidade de 10L) & Utilizado para a incorporação da mistura \\
\hline Funil & Utilizado para filtração \\
\hline Peneira pequena & Utilizado para deixar passar as substâncias reduzidas a pequenos fragmentos \\
\hline Moldes de Plástico & Oferece suporte para o sabão em barra obter formato \\
\hline Balança Analítica & Análise de determinada grandeza sob certas condições ambientais \\
\hline pHmetro & Medidor de pH \\
\hline
\end{tabular}

\section{Produção de sabão sólido (em barra)}

A tabela 2 apresenta os materiais utilizados para a produção do sabão e suas respectivas proporções.

Tabela 2: Materiais utilizados e suas respectivas quantidades para a produção de sabão ecológico em barra.

\begin{tabular}{|l|l|}
\hline MATERIAIS UTILIZADOS & PROPORÇÕES \\
\hline Óleo de cozinha residual & $1 \mathrm{~L}$ \\
\hline Água & $500 \mathrm{~mL}$ \\
\hline Soda Cáustica (NaOH) & $250 \mathrm{~g}$ \\
\hline Amaciante Americano & $300 \mathrm{~mL}$ \\
\hline Sabão em Pó Americano & $300 \mathrm{~mL}$ \\
\hline
\end{tabular}

Em um recipiente plástico com capacidade de $10 \mathrm{~L}$, inseriu-se $500 \mathrm{ml}$ de água, em seguida adicionouse cuidadosamente a soda cáustica até sua completa diluição (lixívia). Em seguida, aqueceu-se o óleo de forma de modo a ficar em estado morno e fora agrupado ao recipiente por 10 minutos. Adicionou-se o amaciante e o sabão em pó e se manteve misturando novamente por 20 minutos até formar uma massa homogênea. Ao final deste processo, colocou-se a mistura em uma forma a fim de moldar o formato do sabão e em repouso permaneceu por 24 horas até o ponto de corte para barras menores. 


\section{Sabão líquido}

A tabela 3 apresenta a configuração dos materiais utilizados e suas respectivas quantidades.

Tabela 3: Materiais utilizados e suas respectivas quantidades para a produção de sabão líquido.

\begin{tabular}{|l|l|}
\hline MATERIAIS UTILIZADOS & PROPORÇÕES \\
\hline Óleo de cozinha residual & $3 \mathrm{~L}$ \\
\hline Água (temperatura ambiente) & $6 \mathrm{~L}$ \\
\hline Soda Cáustica $(\mathrm{NaOH})$ & $1 / 2 \mathrm{~kg}$ \\
\hline Álcool & $1 \mathrm{~L}$ \\
\hline Água (quente) & $4 \mathrm{~L}$ \\
\hline Amaciante Americano & $300 \mathrm{~mL}$ \\
\hline Sabão em Pó Americano & $300 \mathrm{~mL}$ \\
\hline
\end{tabular}

Para a produção do sabão líquido, o processo fora semelhante a produção do sabão em barra. Adicionando $1 \mathrm{~L}$ de água em temperatura ambiente em um recipiente plástico, em seguida acrescentando a soda cáustica até sua completa diluição (lixívia). Diluída toda a soda se aqueceu o óleo sendo adicionado no recipiente por 10 minutos, após esse período acrescentou-se o álcool. Posteriormente $5 \mathrm{~L}$ de água em temperatura ambiente acrescentando o amaciante e sabão em pó. A mistura por 30 minutos ficou em repouso e após esse período se acrescentou $4 \mathrm{~L}$ de água em estado quente. Posto em repouso por 24 horas; com mais $10 \mathrm{~L}$ de água adicionados ao sabão após esse período e mais 5 minutos ao agitar ele esteve pronto para ser utilizado.

\section{Análise Laboratorial}

Em um segundo momento fora realizada a análise laboratorial, essencial para verificação de propriedades de forma experimental do óleo residual e do sabão produzido nesta pesquisa no laboratório de Química da própria Universidade. Visto que no óleo realizou-se os testes de saponificação e acidez. Para o sabão, foram realizados testes de Ph, espuma (sólido e líquido) e viscosidade (líquido).

O índice de pH determina o logaritmo negativo da concentração molar de íons de hidrogênio. Representa convencionalmente a acidez ou a alcalinidade de uma solução. A escala de pH vai de 1 (acido) a 14 (alcalino), sendo que o valor 7 e considerado pH neutro (ANVISA, 2008).

O índice de acidez é determinado para expressar, em miligramas, a quantidade necessária de hidróxido de potássio para a neutralização dos ácidos graxos livres em $1 \mathrm{~g}$ de amostra de óleo. A base do resultado esteve em conformidade com a equação 1 :

$$
I \mathrm{~A}=\frac{V \cdot N .56 .1}{\mathrm{~m}} \quad \text { (Equação 1) }
$$

Em que $V$ é o volume de solução de $\mathrm{NaOH}$ gasto na titulação em mililitros, $N$ é a normalidade da solução e $m$ é a massa da amostra em gramas (MORETTO et al., 1998). Para o procedimento, na ausência de KOH, pode se usar o $\mathrm{NaOH}$ como substituto.

Nezi et al. (2011) apontam que a determinação da quantidade de espuma formada pelo sabão é baseada em uma reação usualmente utilizada em laboratório, reagindo bicarbonato de sódio (NaHCO3) e ácido acético $(\mathrm{CH} 3 \mathrm{COOH}$, presente no vinagre) conforme a Reação 1.

$$
\mathrm{CH} 3 \mathrm{COOH}(\mathrm{I})+\mathrm{NaHCO} 3(\mathrm{aq}) \rightarrow \mathrm{CH} 3 \mathrm{COONa}(\mathrm{aq})+\mathrm{CO} 2(\mathrm{~g})+\mathrm{H} 2 \mathrm{O}(\mathrm{I}) \text { (Reação 1) }
$$

O índice de saponificação é definido como o número de mg de hidróxido de potássio (KOH) 
necessários para saponificar os ácidos graxos, resultantes da hidrólise de uma grama da amostra, é inversamente proporcional ao peso molecular médio dos ácidos graxos dos glicerídeos presentes. Visto que é importante, para acusar a presença de óleos e gorduras de alta proporção de ácidos graxos de baixo peso molecular em misturas com outros óleos e gorduras (MORETTO et al., 1998). Dado pela equação 2.

$$
I S=\frac{(\mathrm{V}-\mathrm{v}) \cdot \mathrm{f} .28}{\mathrm{P}} \quad \text { (Equação 2) }
$$

Em que $(\mathrm{V}-\mathrm{v})$ é a diferença entre o número de $\mathrm{ml}$ de $\mathrm{HCl} 0,5 \mathrm{~N}$ gasto durante as 2 titulações; f representa o fator do $\mathrm{HCl} 0,5 \mathrm{~N}$; P representa o número de gramas da amostra, sendo 28 , equivalente grama de $\mathrm{KOH}$.

O índice de viscosidade segundo Anvisa (2008), consiste em medir a resistência de um material ao fluxo por meio da friç̧ão ou do tempo de escoamento. Fora aplicado o método de Stokes, que conforme Carvalho et al. (2015) é aplicado para os casos de força de fricção experimentada por objetos esféricos que se movem no meio de um fluido viscoso, em um regime laminar. Para objetos esféricos a força viscosa é dada pela formula:

$$
F=6 \pi R \eta v
$$

Em que R é o raio da bolha; $\eta$ representa sua viscosidade dinâmica; e $v$ a sua velocidade. As equações de número 4, 5, 6 e 7 utilizadas para o teste de viscosidade foram baseadas segundo Vyneard:

$$
\begin{gathered}
\rho e s f=\frac{\text { mesf }}{\left(\frac{4}{3}\right) \cdot \pi \cdot r^{3}} \quad \text { (Equação 4) } \\
\rho s a b a ̃ o=\frac{m s a b a ̃ o}{\text { volume }} \quad \text { (Equação 5) } \\
v=\frac{h}{t} \quad \text { (Equação 6) } \\
\eta=\frac{2}{9} \cdot \frac{\rho e s f-\rho s a b a ̃ o}{v} \cdot g \cdot r^{2}
\end{gathered}
$$

(Equação 7)

Sendo: $h=$ altura percorrida; $t=$ tempo percorrido; $m=$ massa; $\eta=$ viscosidade do sabão; $\rho=$ densidade; $v=$ velocidade; $g=$ gravidade; $r$ = raio da esfera.

Para o teste de saponificação baseado em Moretto et al. (1998), pesou-se $2 \mathrm{~g}$ de óleo em um erlenmeyer, em seguida se adicionou $5 \mathrm{~mL}$ de álcool etílico com agitação e posteriormente, 2 gotas de solução alcoólica de fenolftaleina $1 \%$. Realizou-se a titulação com solução $0,1 \mathrm{~N}$ de hidróxido de sódio até que ocorresse a mudança da cor da solução de incolor para rósea. Ao fim da solução, adicionou-se $20 \mathrm{~mL}$ de solução de hidróxido de potássio $4 \%$ com uma bureta. Em seguida, transferiu-se o erlemeyer a um condensador de refluxo e aqueceu até ebulição por 30 minutos. Após resfriamento da solução, adicionou-se 2 gotas de solução alcoólica $1 \%$ de fenolftaleína, e se titulou com uma solução $0,5 \mathrm{~N}$ de $\mathrm{HCl}$ até que ocorresse a mudança de cor da solução de rósea para incolor.

Realizou-se uma titulação em branco onde estavam presentes todos os reagentes. A diferença entre os dois volumes de solução de $\mathrm{HCl}$ está relacionada com a quantidade hidróxido de potássio gasto na saponificação dos ésteres presentes no óleo. 


\section{Teste de Acidez}

Realizado conforme o método de Moretto et al. (1998) se utilizou uma fração de cerca de $2 \mathrm{~g}$ de óleo em um erlenmeyer de $125 \mathrm{~mL}$, em seguida se acrescentou $25 \mathrm{ml}$ da mistura éter etílico: álcool etílico (2:1) com movimentos de agitação. Para a mistura se adicionou 2 gotas de solução alcoólica de fenolftaleína e titulou-se com solução 0,1 $\mathrm{N}$ de hidróxido de sódio até o estágio em que a solução mudasse sua forma incolor para uma coloração rósea e por fim fora calculado o índice de acidez.

Para o teste de pH fora utilizado o Phmetro modelo ION pHB500; onde diluiu-se em um Becker de $100 \mathrm{~mL}$, uma amostra de 2 gramas de sabão em barra em $20 \mathrm{~mL}$ de água destilada, para determinar a alcalinidade do mesmo. Para o teste de espuma, utilizou-se $10 \mathrm{~mL}$ de bicarbonato de sódio (NaHCO3) e 10 $\mathrm{mL}$ de ácido acético $(\mathrm{CH} 3 \mathrm{COOH}$, presente no vinagre). Após a reação pronta, foi diluído em $10 \mathrm{~mL}$ de água, a quantia de $0,5 \mathrm{~g}$ do sabão produzido. Em seguida, essa mesma solução foi adicionada à reação anterior para que pudessem ser feitas as análises necessárias.

No teste de viscosidade, de acordo com Vyneard, se determinou por meio do método de Stokes, onde fora adicionado aproximadamente $20 \mathrm{ml}$ das amostras em provetas de $25 \mathrm{~mL} \mathrm{e}$, em seguida, inseriu-se uma esfera de porcelana na superfície livre do líquido e cronometrou-se o tempo de a bola percorrer determinada altura até o momento de atingir o fundo da proveta.

Após a comprovação das características químicas do produto, o sabão fora separado em porções e doado para dez pessoas a fim de que as mesmas pudessem avaliar a qualidade do produto em suas atividades cotidianas. Funcionários do setor de serviços gerais, da lanchonete da universidade e da comunidade foram contemplados com o material. Para cada um dos envolvidos fora aplicado um questionário no que concerne a eficiência do sabão ecológico. Além de serem realizadas oficinas de produção do sabão ecológico como uma opção de geração de renda e palestras de educação e conscientização sobre a importância da reciclagem do óleo vegetal.

\section{RESULTADOS}

Com a finalização dos testes em laboratório, foram obtidos os seguintes valores para o sabão sólido: 0,561 para o índice de acidez (óleo); 70 mg/1g para o índice de saponificação; 10,41 para o nível de pH e 1 $\mathrm{ml}$ correspondendo ao volume da altura que a espuma atinge na proveta em um tempo de 3 segundos para o teste de espuma, além de ausência de alcalinidade. A partir dos dados encontrados, interpretou-se cada um dos mesmos em conformidade com seu respectivo teste (tabela 4).

Tabela 4: Comparação com a norma ANVISA (2005; 2008).

\begin{tabular}{|l|l|l|l|}
\hline Testes analisados & Índice de acidez & Índice de $\mathbf{p H}$ & Índice de viscosidade \\
\hline $\begin{array}{l}\text { Legislação ANVISA } \\
\text { (2005; 2008). }\end{array}$ & $0,3 \mathrm{mg} \mathrm{KOH} / 100 \mathrm{~g}$ de óleo & $\begin{array}{l}10,4(\mathrm{~S}) \\
10,5(\mathrm{~L})\end{array}$ & $3500-5500 \mathrm{cp}$ \\
\hline Sabão sólido & $0,561 \mathrm{mg} \mathrm{KOH} / 1 \mathrm{~g}$ de óleo & 10,41 & Não aplicável \\
\hline
\end{tabular}

\section{Índice de acidez}

O valor encontrado para o índice de acidez que foi de 0,561 mg de $\mathrm{KOH} / 1 \mathrm{~g}$ de óleo, mostrou-se um 
pouco acima no que tange à legislação vigente, onde o valor estabelecido para o óleo não deve ser superior à $0,3 \mathrm{mg}$ de $\mathrm{KOH} / 1 \mathrm{~g}$ de óleo (ANVISA, 2005). No presente caso, pelo fato do óleo ser reaproveitado em processos de fritura na lanchonete, isso pode ter contribuído para o excedente valor de acidez; por isso recomenda-se que não haja um reuso múltiplo desse material na cozinha pois ele também afeta a saúde dos seres humanos.

\section{Índice de saponificação}

O valor encontrado para o índice de saponificação foi de $70 \mathrm{mg} / 1 \mathrm{~g}$; este valor segundo a norma (Anvisa Resolução no 482 de 23 de setembro de 1999) deve está na faixa de 189-195, porém esta normativa encontra-se revogada pela Resolução $n^{\circ} 270$ de 22 de setembro de 2005 da Anvisa, e a mesma ainda não contempla o valor para padronização ideal deste teste.

\section{Índice de $\mathrm{pH}$}

Com relação ao pH, onde o valor encontrado foi de 10,41. A normativa da ANVISA (2008) estabelece que o pH dos sabões (excetuando-se os casos de sabonetes líquidos neutros), deve estar em torno de 10,4; com isso o pH do sabão apresentado se mostrou estar no nível máximo do limite aceitável.

\section{Índice de espuma}

Para o teste de espuma, a reação aconteceu de forma espontânea e durou apenas alguns segundos, em torno de 15 a 20 segundos para as quantidades utilizadas de reagentes. Para $10 \mathrm{~mL}$ de solução aquosa de bicarbonato de sódio $5 \%$ e a mesma quantidade de vinagre, as bolhas geradas corresponderam a mais ou menos 22 a $27 \mathrm{~mL}$ de volume. Quando houve a adição da solução do sabão ao vinagre, este fez com que a produção de gás carbônico pela reação de bicarbonato de sódio e vinagre acontecesse de forma mais branda e a espuma que agora havia se formado foi a espuma proveniente do sabão.

Após a adição da solução (0,5 g para $10 \mathrm{~mL}$ de água), observou-se que a reação tinha duração de 3 segundos com menor teor de espuma chegando a $1 \mathrm{~mL}$ e não houve persistência de um menor volume de espuma. Vale ressaltar que este teste apenas foi realizado para avaliar mais características do sabão.

\section{Índice de Viscosidade}

Vale ressaltar que se realizou o teste de viscosidade para o sabão líquido produzido. Os resultados obtidos foram de: $h=11,12 \mathrm{~cm} ; t=1,66 \mathrm{seg} ; m=99,1828 \mathrm{~g} ; \eta=4536,03 \mathrm{cp} ; \rho=0,991828 \mathrm{~g} / \mathrm{cm}^{3} ; v=$ $6,69879551807 \mathrm{~cm} / \mathrm{s} ; g=9,8 ; r=0,9615 \mathrm{~cm}$.

Ainda baseado na legislação da ANVISA (2008) a faixa ideal de viscosidade para um sabão liquido é de 3500 - 5500 cp, logo o sabão produzido o qual obteve valor de 4536,03 cp está dentro do aceitável.

\section{Índice de pH (sabão líquido)}

O pH do sabão líquido apresentou 10,62 sendo acima do que estabelece a ANVISA $(10,5)$. 


\section{DISCUSSÃO}

\section{Análise do Questionário}

Acerca dos dados apresentados do questionário contendo oito perguntas, realizado com os auxiliares gerais e funcionários, ambos vinculados a universidade e a comunidade como um todo, averiguamos questões relacionadas à temática do descarte e reaproveitamento do óleo residual e noções de educação ambiental.

O primeiro questionamento se baseava no conhecimento dos entrevistados a respeito das problemáticas que o óleo residual promove quando descartado incorretamente. Constatou-se que os entrevistados tinham conhecimento, ainda que de forma superficial dos potenciais danos que o resíduo causa.

Na segunda questão tratou-se a respeito da compreensão de atividades relacionadas a reciclagem do óleo residual. Notou-se que pelo fato de todos os participantes terem relação direta com a utilização do produto, os mesmos tinham noções de reutilização do resíduo, resultado parecido com a pesquisa de Segatto (2013), que percebeu que $65 \%$ de seus entrevistados tinham noções de formas de reciclagem do óleo. A Figura 2 demonstra uma das principais formas de descarte praticado por quem usa esse tipo de produto.

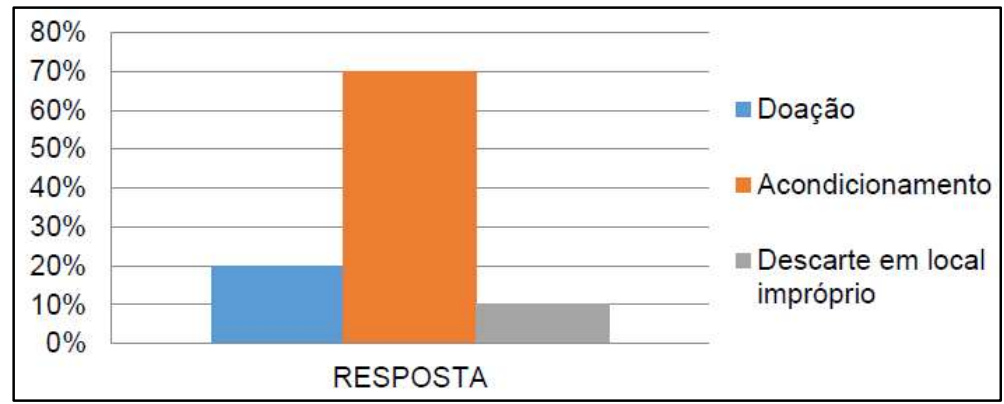

Figura 2: Formas de descarte do óleo de cozinha usado.

As demais questões se relacionavam aos aspectos relacionados a questão comercial do produto desenvolvido no laboratório da UEPA; desta forma se destacou os aspectos: eficiência na geração de limpeza doméstica, textura do produto, percepções organolépticas e apresentação em mercado. Com as análises dos dados obtidos no questionário, observou-se que o produto tem grande potencial de mercado, tendo excelente aceitação entre os entrevistados, o que comprova a possibilidade de geração de renda para as comunidades que venham a desenvolver este produto, o que é exatamente um os propósitos da Lei 12.305/2012, que trata sobre a Política dos Resíduos no Brasil.

Após a aplicação e interpretação do questionário, realizou-se duas oficinas de produção de sabão (figura 3): a primeira no mês de junho com estudantes do próprio campus; e a segunda, em outubro, com a participação de funcionárias do setor de serviços gerais da instituição UEPA e da SEAGRI - Secretaria de Agricultura de Marabá/PA. Sendo essenciais para conscientização e capacitação dos participantes (figura 4), para que pudessem produzir de forma artesanal o próprio sabão.

Sob o aspecto socioeconômico fora possível observar a transformação do óleo de cozinha residual em sabão como um gerador de renda para famílias mais carentes, sendo a venda do sabão sustentável uma 
forma capaz de proporcionar rendimento econômico (SANTOS, 2009).

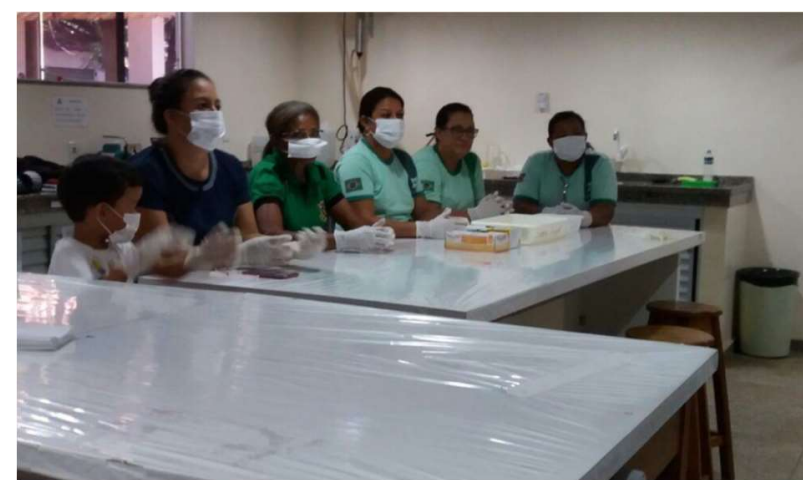

Figura 3: Realização de Palestra.

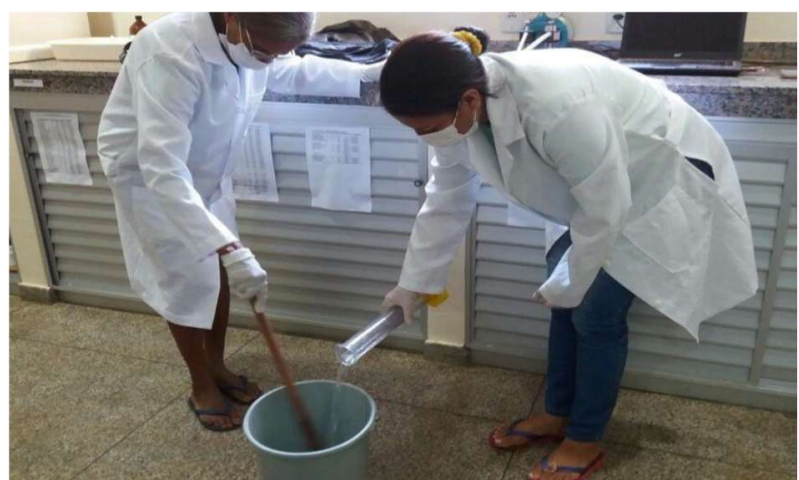

Figura 4: Processo de Produção.

Ao fim das etapas descritas anteriormente, realizou-se uma comparação financeira entre o sabão artesanal e o sabão comercial, (tabela 2 e 3 ) onde foram pesquisadas 3 marcas ( $x, y$ e $z$ ). Notou-se que o sabão ecológico possui um custo muito menor, sendo além de sustentável, econômico e acessível.

Tabela 2: Comparação entre o sabão ecológico em relação ao sabão comercial.

\begin{tabular}{|l|l|l|l|}
\hline PRODUTO & MARCAS & PROPORÇÃO & PREÇO (R\$) \\
\hline \multirow{5}{*}{ Sabão em Barra } & $\mathrm{X}$ & $1 \mathrm{Kg}$ & 6,50 \\
\cline { 2 - 4 } & $\mathrm{Y}$ & $1 \mathrm{Kg}$ & 8,05 \\
\cline { 2 - 4 } & $\mathrm{Z}$ & $1 \mathrm{Kg}$ & 5,80 \\
\cline { 2 - 4 } & Sabão Ecológico & $1 \mathrm{Kg}$ & 3,35 \\
\hline Sabão Líquido & $\mathrm{X}$ & $500 \mathrm{~mL}$ & 10,45 \\
\cline { 2 - 4 } & $\mathrm{Y}$ & $500 \mathrm{~mL}$ & 9,35 \\
\cline { 2 - 4 } & $\mathrm{Z}$ & $500 \mathrm{~mL}$ & 7,99 \\
\cline { 2 - 4 } & Sabão Ecológico & $500 \mathrm{~mL}$ & 1,00 \\
\hline
\end{tabular}

Por meio da produção do sabão ecológico tanto do sólido quanto o líquido, pôde-se estimar o valor do rendimento de cada um, baseado nas receitas adaptadas citadas neste estudo. $O$ sabão sólido que fora colocado em fôrmas retangulares de $35 \mathrm{~cm}$ x $23 \mathrm{~cm}$ rendeu cerca de 13 barras de $200 \mathrm{~g}$ (peso comercial); para o sabão líquido, que fora armazenado em garrafas pet, foram produzidos cerca de $20 \mathrm{~L}$ de detergente (em média o preço comercial é de $\mathrm{R} \$$ 1,00 para um frasco de $500 \mathrm{~mL}$ ). O estudo de Machado et al. (2014) que também aborda a fabricação de sabão artesanal afirma que os experimentos desenvolvidos trouxeram importante contribuição, tanto no aspecto motivacional, econômico e educacional aos envolvidos.

\section{CONCLUSÕES}

A Política Nacional de Resíduos Sólidos em suas disposições determina a destinação final ambientalmente adequada dos rejeitos de modo a evitar danos ou riscos à saúde pública e à segurança e a minimizar os impactos ambientais adversos. A reciclagem do óleo vegetal residual pode contribuir com a redução dos impactos causados pela contaminação de mananciais hídricos e ainda pode ser revertida para a confecção de produtos como o sabão artesanal.

O descarte inadequado do óleo residual de cozinha se tornou recorrente no meio ambiente; por ser uma prática comum da sociedade. Nesse cenário, buscou-se apresentar alternativas de minimização destes impactos e maximização de renda para populações menos favorecidas. Através do desenvolvimento deste 
estudo, fora constatado a viabilidade da aplicação de uma técnica simples, porém eficiente, para o reaproveitamento do óleo de cozinha residual, como a que fora empregada na realização desse estudo: a produção do sabão ecológico tanto em forma líquida quanto sólida.

Por meio da produção do sabão, que aconteceu nas dependências do laboratório de química do campus VIII (Marabá) da Universidade do Estado do Pará e também do compartilhamento dos conhecimentos acerca dos problemas ambientais decorrentes do mau uso do óleo no seu pós-fritura; é evidente que o gerenciamento do mesmo aplicado à logística reversa, se torna uma forma de mitigação e ao mesmo tempo, solução, afim de evitar a poluição ambiental.

Mais que a preservação do meio ambiente e os seus recursos naturais, a reciclagem do óleo para produção de sabão em barra ou líquido gera ganhos econômicos, por ser obtido a um custo inferior que o produto comercial. Constatou-se, com realização das oficinas, que os envolvidos estão se preocupando mais com a preservação do meio ambiente e requisitando mais ações que visam melhorar a qualidade de vida sem prejudicar o meio em que vivem.

Portanto, sugere-se que entidades públicas, privadas e socioambientais promovam em comunidades carentes a produção deste tipo de sabão em larga escala, não somente no território de Marabá, mas ao redor do Mundo, pois a problemática do óleo de cozinha residual atinge não só a população, mas a biodiversidade mundial.

\section{REFERÊNCIAS}

ABIOVE. Associação Brasileira das Indústrias de Óleos Vegetais. Balanço de Oferta: Demanda do Complexo de Soja. São Paulo: ABIOVE, 2017.

ANVISA. Agência Nacional de Vigilância Sanitária. Guia de controle de qualidade de produtos cosméticos. 2 ed. Brasília: ANVISA, 2008.

ANVISA. Agência Nacional de Vigilância Sanitária. Resolução RDC ANVISA/MS n. 270, de 22 de setembro de 2005.

Regulamento Técnico para óleos vegetais, gorduras vegetais e creme vegetal. Brasília: ANVISA, 2005.

BELO, E. J. V.. Reutilização de óleo vegetal para a fabricação de sabão sólido e líquido, na Escola Estadual Professora Maria Belém no município de Barreirinha. Anais Programa Ciência na Escola, v.2, n.1, 2014.

CARVALHO, E. F.; FERNANDES, R. F.; INNOCENTE, S. D. M.; CARDOSO, M. C.; KINDERMANN, C.. O estudo do movimento uniforme usando uma bolha de ar em meio viscoso.

Cadernos Acadêmicos, v.7, n.2, p.134-146, 2015.

MACHADO, L. C.; CIRINO, M. M.. Reciclagem de óleo de cozinha e fabricação de sabão caseiro: Os desafios Da escola pública Paranaense sob a perspectiva do professor PDE. 2014.

MORETTO, E.; FETT, R.. Tecnologia de óleos e gorduras vegetais na indústria de alimentos. São Paulo: Varela Ltda, 1998.
NASCIMENTO, A. C. M.; NASCIMENTO, R. M.; CAETANO, R.. A logística reversa do óleo de fritura usado como solução para problemas ambientais. 2011.

NEZI, S. M.; UHDRE, D. F.; ROMERO, A. L.. Implementação do projeto reciclagem de óleos e gorduras usados em frituras através da fabricação de sabão na UTFPR. In: ENCONTRO DE PRODUÇÃO CIENTÍFICA E TECNOLÓGICA, 6. Anais. Campo Mourão: EPCT 2011.

OLIVEIRA, J. J.. Óleo de fritura usado sendo reaproveitado na fabricação de sabão ecológico. In: CONGRESSO DE INICIAÇÃO CIENTÍFICA DO IFRN, 9. Anais. Natal: IFRN, 2013.

SABESP. Companhia de Saneamento Básico do Estado de São Paulo. Cartilha da Fecomercio: O Uso Racional da Água no Comércio. São Paulo: SABESP, 2010

SANTOS, R. S.. Gerenciamento de Resíduos: Coleta de óleo comestível. Monografia (Bacharelado em Tecnologia em Logística) - Faculdade de Tecnologia da Zona Leste, São Paulo, 2009.

SEGATTO, F. B. B.. Conhecendo as formas de descartes do óleo saturado de cozinha para verificar a educação ambiental na escola. Rev. Elet. em Gestão, Educação e Tecnologia Ambiental, v.10, n.10, p.2122-2129, 2013.

WEYER, M.; NORA, G. D.. Resíduos sólidos domésticos: estudo de caso do óleo vegetal residual no bairro morada da serra Cuiabá/MT. Revista Geonorte, v.6, n.24, p.62-80, 2016.

A CBPC - Companhia Brasileira de Produção Científica (CNPJ: 11.221.422/0001-03) detém os direitos materiais desta publicação. Os direitos referem-se à publicação do trabalho em qualquer parte do mundo, incluindo os direitos às renovações, expansões e disseminações da contribuição, bem como outros direitos subsidiários. Todos os trabalhos publicados eletronicamente poderão posteriormente ser publicados em coletâneas impressas sob coordenação da Sustenere Publishing, da Companhia Brasileira de Produção Científica e seus parceiros autorizados. Os (as) autores (as) preservam os direitos autorais, mas não têm permissão para a publicação da contribuição em outro meio, impresso ou digital, em português ou em tradução. 